\title{
MARUINA MENINA, UMA NOVA ESPÉCIE DE PSYCHODIDAE (DIPTERA) DO BRASIL
}

\author{
Freddy Bravo ${ }^{1}$ \\ Ana Paula Lago ${ }^{1}$
}

\begin{abstract}
MARUINA MENINA, A NEW SPECIES OF PSYCHODIDAE (DIPTERA) FROM BRAZIL. Maruina menina sp. nov., from Atlantic rain forest of Bahia, northeastern Brazil, is described and illustrated.
\end{abstract}

KEYWORDS. Psychodidae, Maruina, new species, Neotropical, Atlantic rain forest.

\section{INTRODUÇÃO}

Do gênero Maruina Müller, 1895, são conhecidas trinta e duas espécies, sendo duas da América do Norte e as outras trinta da Região Neotropical (VAILlant, 1963, 1989; Hogue, 1973, 1990; Wagner, 1988, 1993; Ibañez-Bernal, 1994; Wagner \& Joost, 1994). No Brasil, são conhecidas quatro espécies: Maruina pilosella Müller, 1895 e M. spinosa Müller, 1895 de Itajaí, Santa Catarina; M. garota Hogue, 1973 e M. namorada Hogue, 1973 do Rio de Janeiro. M. pilosella ocorre, também, nos estados de São Paulo (Usina Caiuá, Rancharia) e Rio de Janeiro (Tinguá) (BARretto, 1969) e na Argentina (Tucumán) (QUATE \& WIRTH, 1951).

Hogue (1973) dividiu as espécies de Maruina em dois subgêneros: Maruina (Maruina), caracterizado pelo edeago com espinhos polimórficos (dois ou três formatos distintos) e pela presença do nono tergito nos machos, e Maruina (Aculcina), com espinhos monomórficos no edeago e ausência do tergito nove na terminália dos machos. Todas as espécies brasileiras de Maruina pertencem ao subgênero Maruina (Hogue, 1973).

A seguir, descreve-se uma espécie nova de Maruina (Maruina) da Mata Atlântica da Bahia.

1. Departamento de Ciências Biológicas, Universidade Estadual de Feira de Santana, Av. Universitária s/n, 44031-460, Feira de Santana, BA, Brasil. (fbravo@uefs.br) 


\section{MATERIAL E MÉTODOS}

Os espécimens estudados foram tratados com solução aquosa de hidróxido de potássio $(\mathrm{KOH})$ e montados em lâmina permanente. Os exemplares estão depositados na Coleção Entomológica da Universidade Estadual de Feira de Santana (CUFS), Feira de Santana, Bahia. Segue-se o sistema para a venação alar proposto por Colless \& McAlpine (1991) e as demais terminologias seguem McAlPINE (1981). As medidas estão em milímetros.

Os espécimens foram coletados com armadilha luminosa tipo "Luiz de Queiroz" em Ituberá, Bahia, localidade a aproximadamente $110 \mathrm{~km}$ ao sul de Salvador, em uma mata higrófila, próxima de uma cachoeira conhecida como Pancada Grande, inserida no Bioma Mata Atlântica.

\section{Maruina menina sp. nov.}

(Figs. 1-8)

Material-tipo. BRASIL, Bahia: Ituberá, holótipo o', 12.VI.2002, F. Bravo col. (CUFS). Alótipo \& e parátipos, 9 \& mesmos dados do holótipo (CUFS).

Etimologia. O substantivo específico menina refere-se, no Brasil, às crianças de sexo feminino.

Descrição. Holótipo macho, comprimento do corpo, 1,5. Cabeça subcircular; sutura interocular presente (fig. 1). Palpo maxilar com quatro segmentos; comprimento relativo dos segmentos do palpo: 1,0:2,0:2,0:3,0 (fig. 2). Antena incompleta no exemplar estudado; escapo subcilíndrico; pedicelo menor, subesférico (fig. 3); flagelômeros subcilíndricos, com formato de barril (fig. 3); ascóides perdidos no exemplar estudado. Comprimento da asa, 1,6; largura máxima, 0,36; $\mathrm{Sc}$ ausente; $\mathrm{R}_{1}$ pouco esclerotinizada, não alcançando a $\mathrm{C} ; \mathrm{R}_{2}$ incompleta, não unida a $\mathrm{R}_{2+3}$. $\mathrm{R}_{5}$ bem esclerotinizada, exceto pelo ápice; $\mathbf{M}_{2}$ com base pouco esclerotinizada, não unida a $\mathbf{M}_{1} ; \mathbf{M}_{4}$ bem esclerotinizada; $\mathrm{CuA}$ pouco esclerotinizada (fig. 4). Cercos, gonocoxitos e gonóstilos com pilosidade (figs. 5-7); gonocoxitos com aproximadamente 21 cerdas longas na superfície dorsal. Ápice do esternito $10 \mathrm{com}$ micropilosidade (figs. 5, 7). Tergito 9 sub-retangular (fig. 7). Tergito 10 fundido ao esternito 10, com micropilosidade apical (figs. 5, 7). Cercos compridos, digitiformes, com tenácula apical (figs. 5-7). Esternito 9 estreito, fundido aos gonocoxitos (figs. 5, 6). Gonocoxitos subcilíndricos; gonóstilos digitiformes (figs. 5, 6). Edeago simétrico; espinhos edeagais monomórficos, formados por apenas um par (fig. 6); apódema ejaculador comprido, dorsalmente quase tão longo quanto largo (fig. 6). Apódema gonocoxal, menor que o apódema ejaculador (fig. 5), formado por uma região inferior mais estreita e a superior mais larga, unidas anteriormente (fig. 5).

Fêmea. Semelhante ao macho, exceto pelas características descritas a seguir. Comprimento do corpo 1,7. Comprimento relativo dos segmentos do palpo: 1,0:1,5:1,8:3,5. Comprimento da asa, 1,9; largura máxima, 0,4. Gonocoxito 8 com única apófise, bilobada no ápice (fig. 8). Esternito 9 estreito, mais esclerotinizado no ápice (fig. 8). Cercos com cerdas compridas na extremidade (fig. 8).

Comentários. Maruina menina é incluída no subgênero Maruina por apresentar o esternito 9, característica ausente em todas as espécies do subgênero Aculcina. $\mathrm{O}$ edeago com espinhos monomórficos em M. menina é uma característica observada em todas as espécies do subgênero Aculcina e em uma espécie do subgênero Maruina, M. garota. 


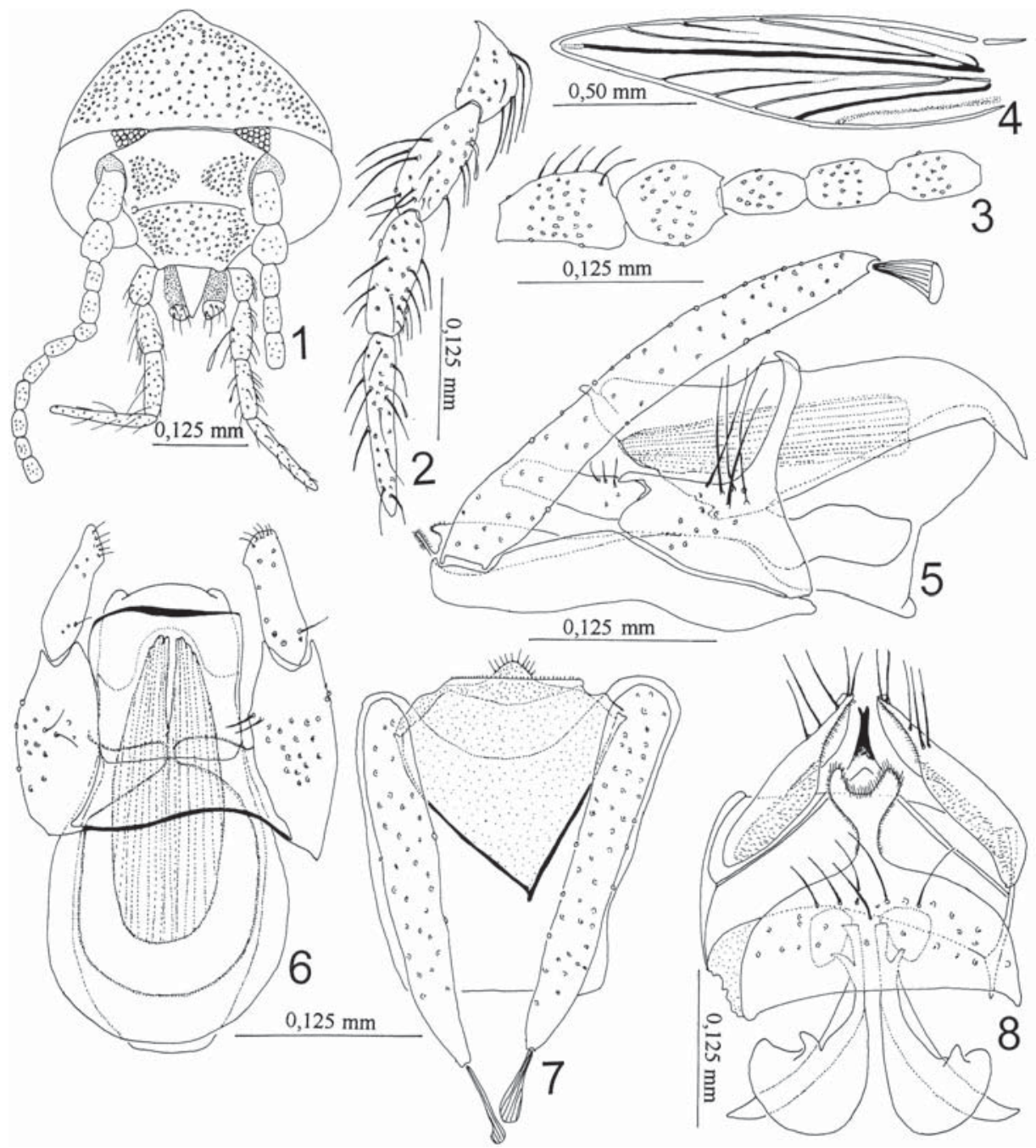

Figs. 1-8. Maruina menina sp. nov. Macho, holótipo: 1, cabeça; 2, palpo maxilar; 3, base da antena, pedicelo, escapo e 3 primeiros flagelômeros; 4, asa; terminália masculina: 5, lateral; 6, dorsal; 7, ventral. Fêmea, alótipo: 8, terminália feminina, ventral. 
Maruina menina diferencia-se de $M$. garota por ter 21cerdas longas no gonocoxito e pelo gonóstilo digitiforme com o ápice truncado; em M. garota o gonocoxito apresenta 23 a 26 cerdas longas e o gonóstilo é curvo, terminando em ponta, queliceriforme.

\section{REFERÊNCIAS BIBLIOGRÁFICAS}

Barretto, M. P. 1969. Sobre o gênero Maruina F. Müller, 1895 (Diptera, Psychodidae). Revta bras. Ent., São Paulo, 2:61-69.

Colless, D. H. \& McAlpine, D. K. 1991. Diptera. In: CSIRO. The insects of Australia. Victoria, Melbourne University. p.717-786.

Hogue, C. L. 1973. A taxonomic review of the genus Maruina (Diptera, Psychodidae). Sci. Bull. Nat. Hist. Mus., Los Angeles, 17:1-69.

1990. A remarkable new species of Maruina (Diptera, Psychodidae) from Colombia Aquatic Insects, Lisse, 12:185-191.

Ibánez-BernaL, S. 1994. Maruina (Maruina) pebeta: a new species of torrenticolous Psychodidae (Diptera) of Cordoba Province, Argentina. Revta bras. Ent., São Paulo, 38(1):57-62.

McAlpine, J. F. 1981. Morphology and terminology: adults. In: McAlpine, J. F.; Peterson, B. V. et al. eds. Manual of Neartic Diptera. Ottawa, Research Branch, Agriculture Canada. v. 1, p.9-63. (Monograph $\mathrm{n}^{\circ} 27$ )

Quate, L. W. \& Wirth, W. W. 1951. A taxonomic revision of the genus Maruina (Diptera: Psychodidae). Wasmann j. biol., San Francisco, 9:151-166.

Vaillant, F. 1963. Les Maruina d'Amérique du Nord (Diptera, Psychodidae). Bull. Soc. ent. Fr., Paris, 68:71- 91.

1989. Les diptères Psychodidae Psychodinae dont les larves sont pourvues de ventouses ventrales. Annls Soc. ent. Fr., (N. S.), Paris, 25:17-23.

Wagner, R. 1988. The first representative of the moth-fly genus Maruina Müller, 1895 from Peru (Diptera: Psychodidae). Stud. Neotrop. Fauna Environ., Lisse, 23:55-57.

1993. On a collection of Psychodidae (Diptera) by Dr. L. Botosaneanu from some caribbean islands. Aquatic Insects, Lisse, 15:109-127.

Wagner, R. \& Joost, W. 1994. On a small collection of Psychodidae (Diptera) from Colombia. Stud. Neotrop. Fauna Environ., Lisse, 29:75-86. 